\title{
Phenotypic and Genotypic Patterns of Beta-Lactam Resistance among Escherichia coli Clinical Isolates
}

\author{
Ghada Hani Ali* \\ Department of Microbiology and immunology, Faculty of pharmacy and Drug Manufacturing, \\ Pharos University, Alexandria, Egypt \\ *Corresponding author
}

\section{A B S T R A C T}

\begin{tabular}{|l|}
\hline K e y w o r d s \\
ESBL, \\
Carbapenemase, \\
MBL, E. coli, \\
PCR, MALDI-TOF \\
\hline Article Info \\
\hline $\begin{array}{l}\text { Accepted: } \\
\text { 28 July 2020 } \\
\text { Available Online: } \\
\text { 10 August } 2020\end{array}$ \\
\hline
\end{tabular}

\section{Introduction}

Bacterial resistance is a major concern for physicians because resistant bacteria, particularly Staphylococci, Pseudomonas species, Escherichia coli and Enterococci, are becoming commonplace in healthcare institutions. Clinically important bacteria are characterized not only by single drug resistance, but also by multidrug resistance (MDR) (Odonkor and Addo, 2011).

Escherichia coli species can lead to a wide range of disease states, notably pneumonia, urinary tract infections (UTIs), septicemia,
The aim of the present study was to determine the phenotypic resistance pattern to $\beta$ lactam antibiotics among Escherichia coli clinical isolates and to identify the genetic determinants responsible for $\beta$-lactam antibiotic resistance. Forty Escherichia coli isolates were included in this study. Identification of tested strains was confirmed using MALDITOF/MS. Phenotypic and genotypic $\beta$-lactamase patterns were investigated. Twelve isolates were resistant to carbapenems, while most of them exhibited resistance to the one or more of the third and fourth generation cephalosporins (ESC) (35 out of 40). Phenotypically, the production of extended-spectrum beta-lactamase (ESBL), metallo- $\beta$ amases (MBL), and carbapenemases was detected in 31, 8, and 15 isolates,

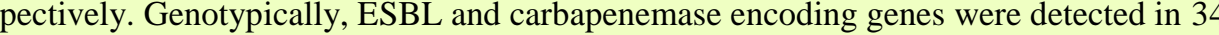
and 19 isolates, respectively. The results of the current study indicate the high prevalence of $\beta$-lactam resistance among Escherichia coli isolates. 
emerging public health problem. ESBLs are enzymes commonly associated with TEM and SHV. Moreover, CTX-M-type ESBLs have emerged within the community, particularly among E. coli and $K$. pneumoniae isolated from UTIs, with a widespread prevalence and multidrug resistance in many countries worldwide(Nathisuwan et al., 2001). Infection with carbapenem-resistant Enterobacteriaceae (CRE) or carbapenemase-producing Enterobacteriaceae is emerging as an important challenge in health-care settings.

The concern is that carbapenem is often used as a drug of last resort when battling resistant bacterial strains. Furthermore, new slight mutations could result in infections for which there is very little, if anything, healthcare professionals can do to treat patients with resistant organisms (Bradford, 2001). Many clinical laboratories have problems in rapid diagnosis and identification of Escherichia coli infection and also in detection of the various $\beta$-lactamases produced by these isolates. Confusion exists about the importance of these resistance mechanisms, optimal test methods, and appropriate reporting conventions. In view of need of cheap and easy methods for the diagnosis of various $\beta$-lactamases in basic microbiological laboratories, a prospective study should be carried out in order to determine resistance mechanism by various $\beta$-lactamases in Escherichia coli clinical isolates using various phenotypic and genotypic methods.

\section{Materials and Methods}

All culture media and antibiotic disks used in this study were purchased from Oxoid (Cambridge, UK).

\section{Collection of clinical isolates}

A total of 40 Escherichia coli isolates were obtained from different clinical samples submitted to the Microbiology Department, Medical Research Institute, Alexandria University. The identification of Escherichia coli isolates was confirmed using matrixassisted laser desorption ionization-time of flight mass spectrometry (MALDI-TOF/MS; Bruker, Billerica, MA, USA).

\section{Antimicrobial susceptibility}

Kirby-Bauer method (Jacoby, 2009) was used for the antimicrobial susceptibility testing of Escherichia coli strains on Mueller-Hinton agar plates. Beta-lactam antibiotics were chosen according to the CLSI recommendations (Clinical and Laboratory Standards Institute, 2017). The disks used were cefotaxime (CTX), ceftriaxone (CRO), ceftazidime (CAZ), cefoxitin (FOX), cefepime (FEP), tazobactam/ piperacillin (TZP), aztreonam (ATM), imipenem (IPM), and meropenem (MEM). The sizes of the inhibition zones were interpreted according to CLSIand the organisms were reported as sensitive, intermediate, or resistant to the agents that have been tested(Clinical and Laboratory Standards Institute, 2017).

\section{$\beta$-lactamases phenotypic characterization}

Strains that were found to be resistant to CAZ and/or FOX were further screened for the presence of extended-spectrum betalactamase (ESBL) hyperproduction, whereas those resistant to IPM and/or MEM were further screened for the presence of carbapenemases and MBL.

\section{Screening for ESBL production}

\section{Combined disk test}

Escherichia coli isolates resistant to CAZ and/or CTX were investigated for ESBL production using combined disk method. Mueller Hinton agar (MHA) was inoculated 
with standard inoculum (0.5 McFarland) of the test isolate. It was tested for ceftazidime $(30 \mu \mathrm{g})$ and ceftazidime- clavulanic acid (30 $\mu \mathrm{g} / 10 \mu \mathrm{g})$. An increase in zone diameter of $\geq$ $5 \mathrm{~mm}$ in the presence of clavulanic acid than ceftazidime alone was interpreted as ESBL producer(Bauer et al., 1966).

\section{Chromogenic medium chromID ESBL}

Each test isolate was inoculated onto ChromID ESBL and incubated for 24 hours at $37^{\circ} \mathrm{C}$. The presence of green, brownish-green colonies of $\beta$-glucosidase-producing Escherichia coliisolates indicates potential ESBL producers(Glupczynski et al., 2007).

\section{Screening for carbapenemase production}

Escherichia coli strains resistant to one or more of the carbapenems were screened for carbapenemase production by modified Hodge test (MHT) using carbapenemsusceptible Escherichia coli as the indicator organism (Huang et al., 2010). MuellerHinton agar plate was inoculated with 0.5 McFarland suspension of the indicator strain. Then, two disks containing IPM $(10 \mu \mathrm{g})$ and MEM $(10 \mu \mathrm{g})$ were placed on the agar plate away from each other. Heavy inoculum of the test strain was streaked onto the MuellerHinton agar plate in a straight line from the edge of one disk to the plate periphery. Carbapenemase production induces a cloverleaf-shaped indentation of growth of the indicator strain after overnight incubation (Huang et al., 2010).

\section{Screening for MBL production}

Overnight broth of the carbapenem resistant test strains was prepared at a $0.5 \mathrm{McFarland}$ standard and spread on MHA plate using cotton swab. Disks of imipenem $(10 \mu \mathrm{g})$ alone and imipenem in combination with EDTA were placed on the plate at a distance of 4-5 $\mathrm{cm}$ from each other. The inhibition zones displayed around the IPM (Oxoid, UK) and the IPM-EDTA (EIP) disks were compared after 16 hours of incubation at $37^{\circ} \mathrm{C}$. The difference of $\geq 7 \mathrm{~mm}$ between the inhibition zone diameter of the EIP disk and that of IPM only disk was considered to be a positive for the presence of MBLs (Coudron, 2005).

\section{Detection of $\beta$-lactamase encoding genes}

Genotypic detection of different $\beta$-lactamase genes belonging to ESBL, carbapenemases and MBL was performed using polymerase chain reaction (PCR). All primers used in this study are listed in Supplementary Tables 1-3. The primers were purchased from Biosearch Technologies (Novato, CA, USA). The PCR Master mixMyTaq HS Red Mix was supplied by BioLine (London, UK). PCR amplification of the extracted DNA was carried out on Veriti Thermal Cycler (Applied Biosystems, CA, USA). Bacterial DNA was extracted by boiling method; shortly 3-4 colonies were suspended in sterile Tris-EDTA buffer to make a heavy suspension. The suspension was incubated in a boiling water bath for 15 min followed by rapid cooling on ice and centrifugation. The supernatant was used as a DNA template. PCR was performed in a total volume of $25 \mu \mathrm{l}$ including $12.5 \mu \mathrm{L} 2 \mathrm{X}$ MyTaq HS Red Mix, 10 picomoles of each primer, and $0.5 \mu \mathrm{l}$ DNA extract. A negative control was prepared by the addition of the same contents to the tube without DNA extract.

\section{Results and Discussion}

The aim of the present study was to determine the phenotypic resistance pattern to $\beta$-lactam antibiotics among Escherichia coli clinical isolates and to identify the genetic determinants responsible for $\beta$-lactam antibiotic resistance. The phenotypic methods of $\beta$-lactamase detection were to be compared with genotypic techniques in an attempt to 
select an easy, cheap and reproducible technique for the detection of these enzymes to be used in clinical laboratories.

The identification of 40 isolates included in this study as Escherichia coli was confirmed using MALDI-TOF/MS. Thirteen isolates included in this study were obtained from urine $(32.5 \%)$ followed by 11 from sputum $(27.5 \%)$. Concerning the remaining 16 isolates, $7(17.5 \%)$ and $9(22.5 \%)$ isolates were isolated from wound and nasal swabs, respectively.

Antibiotic susceptibility testing using KirbyBauer method showed that out of the 40 isolates a total of $33(82.5 \%)$ and $8(20 \%)$ isolates were resistant to third generation cephalosporin and carbapenem, respectively. The detailed results for the disk diffusion test are shown in Table 1.

In a previous survey, a significant increase in the ESBL rate was reported from all parts of the world. The actual magnitude of problem posed by ESBL producers is not known as routine susceptibility testing fails to detect all ESBL producers (Kaftandzieva et al., 2011). $K$. pneumoniae and $E$. coli remain the major ESBL-producing organisms isolated worldwide (Sarojamma and Ramakrishna, 2011)which are recommended to be routinely tested and reported by the CLSI. Prevalence of ESBLs varies from an institute to another. Previous studies have reported ESBL production varying from 4 to $80 \%$ (Jacoby and Munoz-Price, 2005; Shahlol AM et al., 2015).

The first phenotypic test performed for ESBL detection in this study was the CDT. Phenotypic detection of ESBL was carried out using combined disk method and chromID ESBL agar; 30 (75\%) and 33 (82.5\%) Escherichia coli isolates showed ESBL production, respectively.
The CLSI guidelines recommended the CDT as the most trusted phenotypic test for determination of ESBL presence (Clinical and Laboratory Standards Institute, 2017). This technically simple method is considered as an inexpensive alternative for the DDST in the detection of ESBL producers (Abdel-Hady et al., 2008). Expectedly, the CDT that lacks the optimal disk spacing problem shows higher sensitivity than the DSST. This could be observed in our study, whereas30 $(75 \%)$ of the isolates scored a positive result showing an enhancement of $\geq 5 \mathrm{~mm}$ in the zone of inhibition when clavulanic acid was added to the CAZ disk. Similar incidence rate was reported by Dalela et al., (Dalela, 2012).

In the present study all clinical isolates were screened for ESBL producers using chromID ESBL agar, which showed positive results with $33(82.5 \%)$ of the tested isolates. Using PCR as the gold standard, this test showed a sensitivity of $97.1 \%$. This is in partial agreement with Grohs et al., (Rodriguez-Bano and Pascual, 2008) who declared a higher sensitivity of this chromogenic agar (97.5\%). (Grohs is correct reference)

The results of the detection of blaTEM, blaSHV, blaCTX-M, blaCTX-M9 and blaOXA-1 genes among 40 Escherichia coli strains are shown in Table 2. A high prevalence of ESBL-production by Enterobacteriaceae $(78.4 \%)$ was also reported by Alsultan et al., (Grohs et al., 2013). (Alsultan is correct reference) Comparing our results with other studies in Egypt, it was found that our work showed the highest level of ESBL resistance (Afifi, 2013; Alsultan et al., 2013; Abdallah et al., 2015) (remove Alsultan) Possibly, the high prevalence in the Middle East, especially Egypt, is related to the uncontrolled use of antibiotics in these countries, where many drugs are still available over the counter. 
Escherichia coli strains were phenotypically tested for the presence of carbapenemases using MHT, where 10 out of 40 strains were positive. MHT has been used extensively as a phenotypic method for the detection of carbapenemase activity (Birgy et al., 2012), and it is the only carbapenemase detection method recommended by the CLSI for screening purposes. However, there are various shortcomings with MHT. The assay cannot distinguish the type of carbapenemase involved. Most importantly, false-positive results have been observed with isolates producing CTX-M-type ESBLs or increased amounts of AmpC $\beta$-lactamases (cephalosporinases) (Miriagou et al., 2010; Tzouvelekis et al., 2012).

Eight Escherichia coli strains resistant to IPM and/or MEM were phenotypically tested for the presence of MBL using combined disk method. All 8 strains were positive determined using IPM-EDTA combined disk method. The CDT is the most commonly used format of MBL detection assays. In this test, the $\beta$-lactam disk is potentiated with an inhibitor, and the diameter of its inhibition zone is then compared with that of the $\beta$ lactam disk alone. An increase in the inhibition zone diameter above a predefined cut-off value indicates MBL activity (Marchiaro et al., 2005). This test shows high sensitivity even with isolates with low carbapenem resistance levels (Senda et al., 1996; Tzouvelekis et al., 2012). Clinical isolates tested by the IPM/ IPM-EDTA disk method for MBL production may give poor results, perhaps due to involvement of other resistance mechanisms that may interfere with the test (Hrabak et al., 2014).

The results in the present study showed that out of 40 Escherichia coli tested, 8 (20\%) isolates were MBL producers.Yadav and Sharma (2017) (Yadav and Sharma) reported that $7.04 \%$ of the carbapenemase producing
Enterobacteriaceae were found to be MBL producers.

Molecular developments make genotypic detection more readily available and cost effective for diagnostic laboratories to identify different types of ESBLs (Sundsfjord et al., 2004). Previous studies (Thabit et al., 2011; Abdallah et al., 2015) have described various molecular approaches for the rapid screening of ESBL-positive organisms for the presence of different ESBL genes.

In the present work, conventional and multiplex PCR were used in the detection of ESBL-producing clinical strains. Generally, ESBL encoding genes were observed among $34(85 \%)$ isolates. Concerning conventional PCR, bla $a_{\text {OXA-1 }}$ and $b l a_{\text {CTX-9 }}$ were detected in 26 (65) and $21(52.5 \%)$ isolates, respectively. On the other hand, multiplex PCR revealed 34 $(85 \%)$ isolates harbouring bla ${ }_{\mathrm{SHV}}$, followed by bla $a_{\mathrm{CTX}-\mathrm{M}}$ and $b l a_{\mathrm{TEM}}$ in $30(75 \%)$ and 17 (42.5\%) isolates, respectively. Multiplex PCR gave the same results as conventional PCR for bla $_{\mathrm{TEM}}$, bla $_{\mathrm{CTX}-\mathrm{M}}$ and bla $a_{\mathrm{SHV}}$ gene separately. This means that by using multiplex PCR, time, chemicals and cost could be saved. Our results were relatively higher than those reported by most of the previously published studies. For instance, (Paniagua et al., 2010)stated that the distribution of the ESBL enzymes was as follows: bla $a_{\text {CTX-M-9 }}$ group (40\%); bla $a_{\text {CTХ-M-1 }}$ group $(26.6 \%)$; bla $a_{\mathrm{SHV}^{-}}$-type (29\%); and bla TEM$^{-t y p e ~(4.4 \%) . ~}$

Furthermore, the prevalence of ESBLs in the present study varies from others because of the differences in infection control practices between hospitals or due to differences in the use of cephalosporins (Wayne, 2008). On the other hand, the high occurrence of ESBL producers in the current work probably relates to rampant and inadvertent use of thirdgeneration cephalosporins. Over the counter availability could be another cause when 
patients resort to self-medication(Begum and Damle, 2015).

Several Multiplex PCR assays for carbapenemase genes have been described (Poirel et al., 2011; Swayne et al., 2011;
Monteiro et al., 2012) but require real-time PCR facilities or rely on amplicon detection by gel electrophoresis and might therefore not be convenient for all laboratories (Birgy et al., 2012).

Table.1 Resistance of the 40 Escherichia coli isolates to different $\beta$-lactam antibiotics

\begin{tabular}{|l|c|c|c|c|}
\hline \multirow{2}{*}{\multicolumn{1}{|c|}{ Antibiotic }} & \multicolumn{2}{c|}{ Resistant } & \multicolumn{2}{c|}{ Sensitive } \\
\cline { 2 - 5 } & Number & percentage & number & percentage \\
\hline Cefotaxime (CTX) & 33 & 82.5 & 7 & 7.5 \\
\hline Ceftazidime (CAZ) & 31 & 77.5 & 9 & 22.5 \\
\hline Ceftrixone (CRO) & 28 & 70 & 12 & 30 \\
\hline Cefepime (FEP) & 28 & 70 & 12 & 30 \\
\hline Cefoxitin (FOX) & 15 & 37.5 & 25 & 62.5 \\
\hline Aztreonam (ATM) & 24 & 60 & 16 & 40 \\
\hline Tazobactam/Piperacillin (TZP) & 20 & 50 & 10 & 50 \\
\hline Imipenem (IPM) & 8 & 20 & 32 & 80 \\
\hline Meropenem (MEM) & 8 & 20 & 32 & 80 \\
\hline
\end{tabular}

Table.2 ESBL gene detection among 40 Escherichia coli isolates

\begin{tabular}{|l|c|c|c|c|}
\hline & \multicolumn{2}{|c|}{ Positive Results } & \multicolumn{2}{c|}{ Negative Results } \\
\hline & No. & $(\boldsymbol{\%})$ & No. & $(\boldsymbol{\%})$ \\
\hline bla $_{\text {CTX-M9 }}$ & 21 & 52.5 & 19 & 47.5 \\
\hline bla $_{\text {CTX-M }}$ & 30 & 75 & 10 & 25 \\
\hline bla $_{\text {SHV }}$ & 34 & 85 & 6 & 15 \\
\hline bla $_{\text {TEM }}$ & 17 & 42.5 & 23 & 57.5 \\
\hline bla $_{\text {OXA-1 }}$ & 26 & 65 & 14 & 35 \\
\hline
\end{tabular}

Table.3 Genotypic detection of carbapenemases among tested Escherichia coli isolates

\begin{tabular}{|l|c|c|c|c|}
\hline & \multicolumn{2}{|c|}{ Positive Results } & \multicolumn{2}{c|}{ Negative Results } \\
\hline & No. & $(\boldsymbol{\%})$ & No. & $(\boldsymbol{\%})$ \\
\hline bla $_{\text {NDM }}$ & 13 & 32.5 & 27 & 67.5 \\
\hline bla $_{\text {VIM }}$ & 0 & 0 & 40 & 100 \\
\hline bla $_{\text {IMP }}$ & 2 & 5 & 38 & 95 \\
\hline bla $_{\text {KPC }}$ & 4 & 10 & 36 & 90 \\
\hline bla $_{\text {OXA-48 }}$ & 19 & 47.5 & 21 & 52.5 \\
\hline
\end{tabular}

Four $(4 \%)$ isolates were bla $_{\mathrm{KPC}}$ positive, while $2(5 \%), 19(47.5 \%)$ and $13(32.5 \%)$ and isolates marked positive results with bla $_{\mathrm{IMP}}$, bla $a_{\mathrm{OXA}-48}$ and bla $_{\mathrm{NDM}}$, respectively (Table 3 ). The fact that $b l a_{\mathrm{VIM}}$ and $b l a_{\mathrm{IMP}}$ were absent by multiplex PCR may be due to other variants 
of the diverse $b l a_{\mathrm{VIM}}$ and $b l a_{\mathrm{IMP}}$ family. Molecular assays for carbapenemase detection can only detect known carbapenemase genes, while new variants of known carbapenemases might be missed (Kaase et al., 2012). Therefore, phenotypic tests like the modified Hodge test and chromogenic agar still play a role in carbapenemase detection and can additionally be used to identify strains that need molecular testing in order to reduce costs.

Concerning the second multiplex PCR, it was shown that $13(32.5 \%)$ and $19(47.5 \%)$ isolates yielded amplified products for $b l a_{\mathrm{NDM}}$ and $b l a_{\text {OXA-48, }}$, respectively. KPC was included in the second multiplex reaction, but all tested isolates showed negative result. The presence of this gene was speculated, therefore further investigation was done using conventional PCR for $b l a_{\mathrm{KPC}}$ showing amplified product with $4(10 \%)$ isolates. In comparison with our results, Govindaswamy et al., (2019)stated that $61.7 \%$ and $10.6 \%$ were bla $\mathrm{NDM}_{1}$ and bla $_{\mathrm{KPC}}$ positive, respectively, while the prevalence of bla $\mathrm{VII}_{\mathrm{IM}}$, bla $\mathrm{IIMP}_{\mathrm{IM}}$ and bla $\mathrm{OXX}_{\mathrm{O}-48}$ was $30.8 \%, 2.1 \%$ and $5.3 \%$, respectively.

In conclusion, ESBL production is the most common mechanism of resistance to $\beta$ lactams among Escherichia coli. Production of $\beta$-lactamases is in continuous and rapid increase worldwide among Escherichia coli isolates showing multiple antibiotic resistance. Therefore, we recommend the introduction of systemic screening for $\beta$ lactamase producers in the routine diagnostic laboratories is an important issue both for the diagnosis and surveillance purposes. In addition, accurate local periodic reports of the resistance pattern as well as establishment of national central laboratories for data collection and nationwide surveillance studies for $\beta$-lactamase emergence is important and will help in the assessment of the actual prevalence of $\beta$-lactamases in Egypt.

\section{Conflict of Interest}

The authors declare no conflict of interest.

\section{Acknowledgment}

The author thanks Pharos University in Alexandria and Medical technology center for their technical support.

\section{References}

Abdallah, H. M., Wintermans, B. B., Reuland, E. A., Koek, A., al Naiemi, N., Ammar, A. M. et al. 2015. Extended-spectrum $\beta$ lactamase- and carbapenemase-producing enterobacteriaceae isolated from Egyptian patients with suspected blood stream infection. PLoS One 10(5), e0128120.

Abdel-Hady, H., Hawas, S., El-Daker, M. and ElKady, R., 2008. Extended-spectrum betalactamase producing Klebsiella pneumoniae in neonatal intensive care unit. J. Perinatol. 28(10), 685-690.

Adekunle, O. O., 2012. Mechanisms of antibacterial resistance in bacteria, general approach. Int. J. Pharma. Med. Biol. Sci. 1(2), 166-187.

Afifi, M. M., 2013. Detection of extended spectrum beta-lactamase producing klebsiella pneumoniae and Escherichia coli of environmental surfaces at Upper Egypt. Int. J. Biol. Chemis. 7(2), 58-68.

Alsultan, A. A., Aboulmagd, E. and Amin, T. T., 2013. ESBL-producing $E$. coli and $K$. pneumoniae in Al-Ahsa, Saudi Arabia: antibiotic susceptibility and prevalence of blaSHV and blaTEM. J. Infect. Dev. Ctries 7(12), 1016-1019.

Bauer, A. W., Kirby, W. M., Sherris, J. C. and Turck, M., 1966. Antibiotic susceptibility testing by a standardized single disk method. Tech. Bull. Regist. Med. Technol. 36(3), 49-52.

Begum, F. and Damle, A. S., 2015. Genotypic detection of extended-spectrum $\beta$ lactamase-producing Klebsiella pneumoniae in a Tertiary care hospital. Int. J. Biomed. Adv. Res. 6(2), 91-97.

Birgy, A., Bidet, P., Genel, N., Doit, C., Decre, 
D., Arlet, G. et al. 2012. Phenotypic screening of carbapenemases and associated beta-lactamases in carbapenemresistant Enterobacteriaceae. J. Clin. Microbiol. 50(4), 1295-1302.

Bradford, P. A., 2001. Extended-spectrum betalactamases in the $21^{\text {st }}$ century: characterization, epidemiology, and detection of this important resistance threat. Clin. Microbiol. Rev. 14(4), 933-951.

Clinical and Laboratory Standards Institute. 2017. M100 Performance Standards for Antimicrobial Susceptibility Testing $\left(27^{\text {th }}\right.$ ed.). Clinical and Laboratory Standards Institute, USA.

Coudron, P. E., 2005. Inhibitor-based methods for detection of plasmid-mediated AmpC $\beta$ Lactamases in Klebsiella spp.,Escherichia coli, and Proteus mirabilis. J. Clin. Microbiol. 43(8), 4163-4167.

Dalela, G., 2012. Prevalence of extended spectrum beta lactamase (ESBL) producers among gram negative bacilli from various clinical isolates in a tertiary care Hospital at Jhalawar, Rajasthan, India. J. Clin. Diagn. Res. 6 (2), 182 -187.

Glupczynski, Y., Berhin, C., Bauraing, C. and Bogaerts, P., 2007. Evaluation of a New Selective Chromogenic Agar Medium for Detection of Extended-Spectrum $\beta$ Lactamase-Producing Enterobacteriaceae. J. Clin. Microbiol. 45(2), 501-505.

Govindaswamy, A., Bajpai, V., Khurana, S., Batra, P., Mathur, P. and Malhotra, R., 2019. Prevalence and Characterization of Carbapenemase-producing Escherichia coli from a Tertiary Care Hospital in India. J. Glob. Infect. Dis. 11(3), 123-124.

Grohs, P., Tillecovidin, B., Caumont-Prim, A., Carbonnelle, E., Day, N., Podglajen, I. et al. 2013. Comparison of five media for detection of extended-spectrum Betalactamase by use of the wasp instrument for automated specimen processing. J. Clin. Microbiol. 51(8), 2713-2716.

Hrabak, J., Chudackova, E. and Papagiannitsis, C. C., 2014. Detection of carbapenemases in Enterobacteriaceae: a challenge for diagnostic microbiological laboratories. Clin. Microbiol. Infect. 20(9), 839-853.

Huang, T. D., Bogaerts, P., Berhin, C., Guisset, A. and Glupczynski, Y., 2010. Evaluation of Brilliance ESBL agar, a novel chromogenic medium for detection of extendedspectrum-beta- lactamase-producing Enterobacteriaceae. J. Clin. Microbiol. 48(6), 2091-2096.

Jacoby, G. A., 2009. AmpC beta-lactamases. Clin. Microbiol. Rev. 22(1), 161-182.

Jacoby, G. A. and Munoz-Price, L. S., 2005. The new beta-lactamases. N. Engl. J. Med. 352(4), 380-391.

Kaase, M., Szabados, F., Wassill, L. and Gatermann, S. G., 2012. Detection of carbapenemases in Enterobacteriaceae by a commercial multiplex PCR. J. Clin. Microbiol. 50(9), 3115-3118.

Kaftandzieva, A., Trajkovska-Dokic, E. and Panovski, N., 2011. Prevalence and molecular characterization of Extended Spectrum Beta-Lactamases (ESBLs) producing Escherichia Coli and Klebsiella Pneumoniae. Prilozi 32(2), 129-141.

Marchiaro, P., Mussi, M. A., Ballerini, V., Pasteran, F., Viale, A. M., Vila, A. J. et al. 2005. Sensitive EDTA-based microbiological assays for detection of metallo-\{beta\}-lactamases in nonfermentative gram-negative bacteria. J. Clin. Microbiol. 43(11), 5648-5652.

Miriagou, V., Cornaglia, G., Edelstein, M., Galani, I., Giske, C. G., Gniadkowski, M. et al. 2010. Acquired carbapenemases in Gram-negative bacterial pathogens: detection and surveillance issues. Clin. Microbiol. Infect. 16(2), 112-122.

Monteiro, J., Widen, R. H., Pignatari, A. C., Kubasek, C. and Silbert, S., 2012. Rapid detection of carbapenemase genes by multiplex real-time PCR. J. Antimicrob. Chemother. 67(4), 906-909.

Nathisuwan, S., Burgess, D. S. and Lewis, J. S., 2001. Extended-spectrum beta-lactamases: epidemiology, detection, and treatment. Pharmacotherapy 21(8), 920-928.

Odonkor, S. T. and Addo, K. K., 2011. Bacteria resistance to antibiotics: Recent trends and challenges. Int. J. Biol. Med. Res. 2(4), 1204-1210.

Paniagua, R., Valverde, A., Coque, T. M., Baquero, F. and Canton, R., 2010. Assessment of prevalence and changing 
epidemiology of extended-spectrum betalactamase-producing Enterobacteriaceae fecal carriers using a chromogenic medium. Diagn. Microbiol. Infect. Dis. 67(4), 376379.

Podschun, R. and Ullmann, U., 1998. Klebsiella spp. as nosocomial pathogens: epidemiology, taxonomy, typing methods, and pathogenicity factors. Clin. Microbiol. Rev. 11(4), 589-603.

Poirel, L., Walsh, T. R., Cuvillier, V. and Nordmann, P., 2011. Multiplex PCR for detection of acquired carbapenemase genes. Diagn. Microbiol. Infect. Dis. 70(1), 119-123.

Rodriguez-Bano, J. and Pascual, A., 2008. Clinical significance of extended-spectrum beta-lactamases. Expert Rev. Anti. Infect. Ther. 6(5), 671-683.

Sarojamma, V. and Ramakrishna, V., 2011. Prevalence of ESBL-producing Klebsiella pneumoniae Isolates in Tertiary Care Hospital. ISRN Microbiol. 2011, 318348.

Senda, K., Arakawa, Y., Ichiyama, S., Nakashima, K., Ito, H., Ohsuka, S. et al. 1996. PCR detection of metallo-beta-lactamase gene (blaIMP) in gram-negative rods resistant to broad-spectrum beta-lactams. J. Clin. Microbiol. 34(12), 2909-2913.

Shahlol AM, Abukhres OM and Taher, I. A., 2015. Prevalence and characterization of extended-spectrum $\beta$-Lactamase-producing enterobacteriaceae in Brack-Alshati, Fezzan, Libya. EC Microbiology 1(1), 2332.
Sundsfjord, A., Simonsen, G. S., Haldorsen, B. C., Haaheim, H., Hjelmevoll, S. O., Littauer, P. et al. 2004. Genetic methods for detection of antimicrobial resistance. APMIS 112(11-12), 815-837.

Swayne, R. L., Ludlam, H. A., Shet, V. G., Woodford, N. and Curran, M. D., 2011. Real-time TaqMan PCR for rapid detection of genes encoding five types of nonmetallo- (class A and D) carbapenemases in Enterobacteriaceae. Int. J. Antimicrob. Agents 38(1), 35-38.

Thabit AG, Ibrahim MA and Attia, A. E., 2011. Detection of extended-spectrum betalactamases (ESBLs) produced by Escherichia coli urinary pathogens at Assiuy hospital. Bull Pharm. Sci. 34, 93103.

Tzouvelekis, L. S., Markogiannakis, A., Psichogiou, M., Tassios, P. T. and Daikos, G. L., 2012. Carbapenemases in klebsiella pneumoniae and other Enterobacteriaceae: An evolving crisis of global dimensions. Clin. Microbiol. Rev. 25(4), 682-707.

Wayne, P. A. 2008. Performance Standards for Antimicrobial Susceptibility Testing. 18th Informational Supplement: M100-S18. Clinical and Laboratory Standards Institute, Wayne.

Yadav, K. and Sharma, N., 2017. Detection of ESBL \& MBL producing E. Coli from urine samples in a tertiary care hospital in Jaipur, Rajasthan. Sch. J. App. Med. Sci. 5(4A), 1259-1272.

\section{How to cite this article:}

Ghada Hani Ali 2020. Phenotypic and Genotypic Patterns of Beta-Lactam Resistance among Escherichia coli Clinical Isolates. Int.J.Curr.Microbiol.App.Sci. 9(08): 3857-3865. doi: https://doi.org/10.20546/ijcmas.2020.908.444 